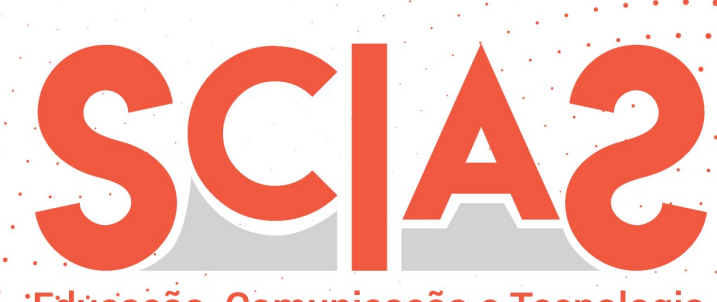

'Edúçaçã̃o, Comunicação e Tecnologia'

Atribuiçãa BB CY 4.0

\title{
Utilização das tecnologias para defender os direitos das mulheres em tempos de pandemia
}

Maria Eliane Alves de Sousa ${ }^{1}$

\section{Resumo}

Neste estudo pretende-se identificar como a sociedade respondeu à necessidade de defesa e garantia dos direitos das mulheres, vulnerabilizados devido à pandemia de Covid-19. Propõe-se uma reflexão sobre as ações efetuadas por meio das tecnologias da informação e comunicação, potencializadas pela internet, para defender e garantir os direitos das mulheres brasileiras ameaçados e violados durante o período da atual pandemia.A pesquisa é bibliográfica e documental em relatórios governamentais e das Nações Unidas, e textos acadêmicos. A abordagem de análise crítica considera a proteção e a justiça social, na perspectiva dos direitos humanos das mulheres.Conclui-se que a doença demonstrou a importância das conexões para que a humanidade supere as crises com solidariedade utilizando o que de melhor tem construído e inventado em prol das mulheres, vulnerabilizadas pelas desigualdades sociais. Demonstra as possibilidades de se ser e ter sociedades inclusivas e sem discriminações, capazes de modificar suas estruturas e sistemas em prol dos princípios democráticos de liberdade, igualdade e sororidade.

\section{Palavras-chave}

Direitos humanos. Tecnologias digitais. Direitos das mulheres. Igualdade de gênero.

Recebido em: 01/o8/2020

Aprovado em: 26/01/2021

\footnotetext{
${ }^{1}$ Doutoranda em Direito pela Universidade Federal da Bahia (Salvador/Bahia/Brasil). Mestre em Saúde Pública pela Fundação Oswaldo Cruz (RJ). Advogada. Professora da Universidade Estadual da Bahia.

E-mail: measud7@gmail.com
} 


\section{Use of technologies to defend women's rights in times of pandemic}

\section{Abstract}

This study aims to identify how society responded to the need to defend and guarantee the rights of women, whowere vulnerable due to the Covid-19 pandemic. It is proposed to reflect on the actions taken by means of information and communication technologies, enhanced by the internet, to defend and guarantee the rights of Brazilian women threatened and violatedduring the current pandemic period. The research is bibliographic and documentary in government and United Nations reports, and academic texts. The critical analysis approach considers protection and social justice, from the perspective of women's human rights. It is concluded that the disease demonstrated the importance of connections for humanity to overcome crises with solidarityusing the best it has built and invented for women, vulnerable by social inequalities. It demonstrates the possibilities of being and having inclusive and nondiscriminatorysocieties, capable of modifying their structures and systems in favor of the democratic principles of freedom, equality and sorority.

\section{Keywords}

Human rights. Digital technologies. Women's rights. Gender equality. 


\section{Introdução}

Vivencia-se um momento excepcional trazido pela pandemia de Covid-19, tanto pelas implicações que a doença em si desencadeia para a saúde e a vida, quanto pelosefeitos negativos de dificuldades sociais, econômicas, laborais, políticas e jurídicas para a sociedade. O que exacerbou as desigualdades sociais, e a forma como estas influenciam o maior acometimento, agravamento e impactos dessa doença para os grupos sociais mais vulneráveis (como: idosos, pessoas em situação de pobreza e mulheres).

As medidas sanitárias (quarentena, isolamento, restrição de mobilidade e locomoção, higiene, sanitização etc.), adotadas para conter a propagação dessa doença exigem severas mudanças no cotidiano, nas liberdades, na propriedade,nos modos de trabalhar e em outras interações sociais.Tais medidas constituem-se é um grande desafio para todas as pessoas, principalmente para esses grupos vulneráveis porque exigem condições e recursos que não estão acessíveis ou o são de modo precário e insuficiente.

Porém, a pandemia também trouxe outras revelações importantes. Para os fins deste estudo, pode-se falar de dois destaques. A primeira, a capacidade humana de reagir em prol de valores éticos e morais, de maneira ética planetária, através da qual as vidas de todos os seres em todos os lugares são importantes para todas (os). E a segunda, a relevância das tecnologias da informação e comunicação para a sociedade como um todo, para as suas necessidades e atividades já conhecidas e também para as excepcionalmente postas pela pandemia. Sob esta perspectiva, essa doença mostra dois pontos basilares para a superação de desigualdades e de crises: as conectividades e a solidariedade.

Neste estudo pretende-se identificar como a sociedade respondeu à necessidade de defesa e garantia dos direitos das mulheres, vulnerabilizados devido à pandemia de Covid-19. Propõe-se uma reflexão sobre as ações efetuadas por meio das tecnologias da informação e comunicação, potencializadas pela internet, para defender e garantir os direitos das mulheres brasileiras ameaçados e violados durante o período da atual pandemia. Para isto apresenta 
alguns relatos de práticas e iniciativas implementadas por entidades governamentais e não governamentais durante a crise da Covid-19, em três áreas cruciais e críticas em relação à defesa das causas das mulheres: a dupla ou tripla jornada de trabalho, pelo acumulo com as tarefas domésticas e de maternidade; a violência doméstica, que ainda é um flagelo e uma pandemia de torturas e assassinatos; e a situação econômica e de acesso a recursos básicos, porque a pobreza acomete a maioria das brasileiras.

Nessas áreas ainda há muitas resistências sociais, culturais e econômicas que alimentam a persistência das altas ocorrências de violências, discriminações, opressões e desigualdades. Resistências e persistências que foram majoradas nessa pandemia. Por tais aspectos a discussão é importante, uma vez que não se pode admitir o retrocesso ou anulação de direitos, bem como a banalização e menosprezo às dificuldades e desigualdades sociais que as mulheres sofrem. $\mathrm{O}$ tema de defesa dos direitos humanos das mulheres dialoga com a educação e a utilização dos diversos meios e recursos tecnológicos, uma vez que além de leis necessita de práticas e recursos pedagógicos - dentro e fora da educação formal - que desconstruam padrões e comportamentos contrários à liberdade e igualdade de gênero.

A pesquisa é bibliográfica e documental em relatórios governamentais e das Nações Unidas, e textos acadêmicos. Também incorpora informações da literatura cinza coletadas em sites de organizações e movimentos de defesa das mulheres. A abordagem de análise crítica considera a proteção e a justiça social, na perspectiva dos direitos humanos das mulheres. Não se pretende esgotar o tema, apenas uma abordagem introdutória para delinear os traços gerais da questão suscitada para a reflexão. Outrossim, também a limitação temporal, uma vez que a pandemia ainda não cessou, consideram-se os dados de março a junho 2020.

\section{Notas sobre defesa de direitos humanos e solidariedade}

De modo simples, cabe esclarecer alguns termos para destacar seus alcances e limites nos contextos em que serão utilizados, bem como a importância destes 
para a vida e o cotidiano que se pretende retratar, mais do que para os conhecimentos e práticas jurídicas formais.

Consoante explanam Akemiet al (2017, p.7), dia a dia presencia-se ou se é informado de situações nas quais pessoas são "humilhadas e tratadas como se fossem meros objetos”. Daí que a ideia de direitos humanos associa-se à capacidade humana de indignar-se com o desrespeito e a desproteção às pessoas frente a tais situações. Os direitos humanos são uma construção da humanidade através da Declaração dos Direitos Humanos após a II Guerra Mundial, que estabelecem parâmetros pelos quais cada pessoa (independentemente da condição social, nacionalidade, gênero, raça e outras características), deve ser tratada pelo Estado, comunidades e famílias. Não se pode aceitar que regimes políticos ou práticas sociais, culturais, econômicas, laborais, científicas, religiosas e outras atentem contra a dignidade humana.

As mulheres estão amparadas pela Declaração dos Direitos Humanos, e de forma específica, a Declaração e Programa de Ação de Viena (1993) reconhece os direitos das mulheres e das meninas como parte integrante e indivisível dos direitos humanos universais. A Declaração e Plataforma de Ação de Pequim (1995) estabelece a superação dos padrões de desigualdade de gênero, devendo o governo e a sociedade criar as condições e apoiar as mulheres nesse processo (ONU MULHERES, s.d.). Além destas normas, as brasileiras possuem o amparo da Constituição Federal, de leis específicas para a violência contra as mulheres (Maria da Penha e Feminicídio), e de outras categorias de mecanismos de defesa, planos e programas nacionais (políticas públicas) para o empoderamento feminino e garantia de direitos sociais e econômicos.

Também há modos de defesa e garantia dos direitos humanos realizados de maneira não jurídica ou estatal por membros da sociedade civil. É a estratégia denominada advocacy (defesa da causa),recurso proativo coletivo em defesa da condição plena de um direito como parte da reflexão crítica dos agentes sociais, para gerar uma resposta social frente às necessidades sociais em um determinado território sem a perda de sua identidade. A linguagem dos direitos humanos é ajustada às necessidades da comunidade, para promover 
mobilização social e institucional, a fim de que a sociedade defenda mudanças políticas, e para enfrentamento da falta dos recursos sociais. Nesta estratégia, o advogado pode ser qualquer pessoa, não precisa ser bacharel em Direito, por ser uma participação democrática e livre. Na América Latina, volta-se para a luta por melhores condições de vida e por equidade, para ampliar a participação e representação de grupos minoritários excluídos, e assegurar que seus direitos sejam garantidos. Deste modo, baseia-se em direitos humanos e em colaboração, solidariedade (CANEL; CASTRO, 2008, p.78-83; MORGADO; GOZETTO, 2017, p.6-10).

Nesse sentido, a solidariedade não representa um dever obrigacional jurídico de âmbito privado. Mas sim o sentimento de agir espontâneo, como valor ético e moral comum das pessoas que integram a sociedade, como interdependência recíproca e empatia, fundado na necessidade de auxílio mútuo na convivência social. Segundo explica Moraes (2008, p.237) a solidariedade fática surge da necessidade da coexistência, e a solidariedade como valor surge da consciência racional dos interesses comuns que implicam uma forma de reciprocidade, indicativa de que "'a cada um que, seja o que for que possa querer, deva fazê-lo pondo-se de algum modo no lugar de qualquer outro"..E com o reforço da dicção de Cardoso (2013, p.133), a solidariedade é a expressão mais profunda da sociabilidade da pessoa humana, e por isto a Constituição Federal a consolida no art. $3^{\circ}$ como premissa necessária para que todos construam uma sociedade livre e justa. Deste modo, depreende-se que o destaque da solidariedade como valor ético e moral comum é a dignidade da pessoa humana.

Cabe transportar a solidariedade para o campo de defesa dos diretos das mulheres, destacando-a como sororidade. Tomada em sentido amplo, sororidade é a união em defesa das causas das mulheres, por toda a sociedade e não apenas pelas mulheres. O termo provém do latim sóror, que significa irmã, e é considerado a versão feminina da fraternidade (frater, irmão em latim). As desigualdades, injustiças e discriminações que as mulheres sofrem decorrem de aspectos da mentalidade machista, do sentido de superioridade baseado no patriarcado e na colonialidade em relação ao gênero, raça, etnia, poder aquisitivo, classe social, estética, geração, nível educacional, profissão etc. que 
perpetuam padrões de dominação, exclusão e estereótipos (CARVALHO e RODRIGUES, 2017, p.2-4; LAGARDE, 2016, p.28). Estas atitudes refletem uma cultura misógina, de depreciação da mulher. A sororidade fundamenta a consciência crítica contra a misoginia que atinge todas as mulheres, como construção de uma mobilização social e política.

Conforme elucida Lagarde (2016, p.27-36), a sororidade é uma dimensão ética, política e prática do feminismo contemporâneo, uma experiência subjetiva de mulheres em busca de relações positivas e à aliança existencial e política, como apoio recíproco para se conseguir o poder para todas, em paralelo com a transformação da solidariedade. Objetiva defender de ataques, agressões e qualquer forma de violência e abuso, do desrespeito aos direitos humanos; e como prevenção da autocomplacência, vitimização e opressão das mulheres.

Então, pode-se compreender que a sororidade é uma forma de empoderamento para as mulheres, que articula lutas e alternativas de intervenções. Portanto, ao mesmo tempo implica cooperação e solidariedade. E, no entendimento de Alves (2014, p.72; 77), incorpora uma proposta educativa que almeja a superação e resistência à institucionalização da exclusão, numa perspectiva integradora de aprendizagem multidimensional da construção coletiva dos saberes das mulheres; como educação, contribui na organização de uma sociedade socialmente justa, tolerante, que respeita o outro, como valores básicos para um mundo melhor.

\section{Usos das tecnologias em prol das causas das mulheres em tempos de pandemia}

A mobilização e a atuação da sociedade civil têm se destacado como estratégia essencial para o combate dos efeitos da pandemia de Covid-19, não apenas na área sanitária, como também econômica, social e cultural. Esta atuação tem se mostrado fundamental especialmente para grupos em maior situação de vulnerabilidade, como as mulheres. A pandemia colocou em perigo de retrocesso todos os avanços já conquistados contra as múltiplas formas de desigualdades de gênero. A nova doença está aprofundando as desigualdades preexistentes, que por sua vez estão ampliando seus impactos na vida de 
mulheres e meninas, negando-lhes oportunidades e comprometendo o desenvolvimento humano destas (ONUMULHERES, 2020).

Esse alerta foi dado pelas Nações Unidas em nível mundial. No Brasil, os problemas gerados pelos efeitos da pandemia começaram a ser divulgados pela mídia, órgãos públicos, organizações e entidades civis. De início com maior atenção para o aumento da violência doméstica contra as mulheres, posteriormente outras violações de direitos foram expostas para serem combatidas.

Nesse contexto, a comunicação através das novas tecnologias da informação e comunicação da internet e telefonia móvel, tem sido uma grande estratégia de mobilização, cooperação e colaboração social nesses tempos de pandemia. Seu uso está na linha de frente para diminuir a lacuna entre as respostas à pandemia e as mulheres, tanto na atuação de combate a desinformação quanto na articulação de espaços de trocas,sociabilidades e de formas de adaptação nesse novo contexto.Os modos de engajamento têm sido diversificados, ocorrendo por meio de enfretamento à violência doméstica, campanhas e parcerias para arrecadação de recursos ou por meio de articulação junto ao poder público.

A violência contra as mulheres é um problema social que se alargou em complexidade nesse período, porque as mulheres enfrentam um elemento condicionante e limitante, que é o isolamento social de prevenção à Covid-19, o que as deixou mais em contato com os violentadores em casa. E se tornou um obstáculo ao acesso à denúncia e medidas protetivas pelos meios outrora existentes e disponíveis, pelas impossibilidades de locomoção, acesso às delegacias e contato com agentes policiais.Segundo dados oficiais, o número de denúncias de violência doméstica aumentou em até 50\%, ao longo do primeiro mês da pandemia (FIOCRUZ, 2020, s.n.p.).

A reação social aconteceu mediante denúncias e medidas emergenciais pelas mídias, movimentos de mulheres e organizações de defesa das mulheres. Um dos grandes aliados do enfrentamento foi o uso das redes sociais. Muitas mulheres em situação de violência doméstica não têm como fazer a denúncia 
por conta própria, por medo ou porque não têm acesso à internet ou a telefonia móvel. Entretanto, essas tecnologias possibilitam que outras pessoas denunciem, facilitando assegurar às vítimas as medidas de proteção necessárias.Esse tipo de ação tornou-se necessária e não configura invasão de privacidade. O importante é que as denúncias cheguem ao sistema policial e de Justiça (CNJ, 2020, s.n.p.).

Diante da gravidade da situação e das dificuldades encontradas para o enfretamento dessa violência, entidades dos poderes estatais criaram novas formas de acesso ao aparato policial e jurídico, pela ampliação e concentração das atividades de garantias e proteção em eventos de mídia social e eventos virtuais, tais como: aumento da capacidade da rede de atendimento on-line; divulgação dos serviços da rede de atendimento à mulher em situação de violência, em farmácias, estabelecimentos de saúde, supermercados e sítios eletrônicos;disponibilização pelo Whatsapp e outros aplicativos orientações sobre leis, direitos e serviços, para meninas e mulheres, e para a comunidade; incentivo ao preenchimento de formulários de avaliação de risco on-line, e encaminhar aos e-mails das delegacias de polícias; e disponibilização de formas remotas gratuitas de denúncias telefônica ou portal eletrônico ou aplicativos de celular (MMFDH, 2020, s.n.p.).

No âmbito do trabalho, a pandemia agravou a situação de desigualdades e vulnerabilidades por vários motivos, principalmente para as que são mães e/ou chefes de família, por causa da dupla jornada para conciliar o trabalho produtivo e o de cuidados do lar e família; o aumento do trabalho não remunerado e o maior risco de desemprego por discriminação de gênero. Inclusive para as que estão home office. As campanhas de incentivo à divisão de tarefas domésticas e cuidados com filhos e/ou parentes entre as mulheres, os homens e outros membros da família de maneira igualitária ganham espaço e adesão através programas em sites da internet, podcasts, redes sociais, cursos on line gratuitos e filmes educativos(ONU, 2020).

No tocante à situação econômica, financeira e de acesso a recursos básicos, inclusive alimentação, ressalta-se a atuação em prol das mulheres em situação 
de pobreza.Vivem em condições precárias de vida não possuem saneamento básico e abastecimento de água potável; habitam em casas muito pequenas, aglomeradas e superlotadas; a preocupação com a sobrevivência sobrepõe-se à necessidade de manter o isolamento social; entre as que trabalham, a maioria está no mercado informal, o mais atingido pelas medidas sanitárias e pela crise econômica (ONU, 2020).

A pandemia destaca as desigualdades de todos os tipos. Representa o maior risco para a saúde dos mais vulneráveis e seus impactos socioeconômicos concentram-se naqueles que são menos capazes de lidar com eles. A menos que ajamos agora, mais 100 milhões de pessoas poderão ser empurradas para a extrema pobreza e poderemos ver a fome em proporções históricas. A maioria das pessoas que estarão nessa situação (60\%) são mulheres e meninas." (GUTERRES, 2020, s.n.p.).

A solidariedade mobilizou a sociedade que, através de ações voluntárias de organizações não governamentais, grupos e coletivos de mulheres (em especial de mulheres negras), entidades religiosas e empresas do setor privado montaram redes de enfrentamento e colaboração contra as desigualdades as desigualdades sociais e econômicas. As ações de campanhas de doações de alimentos, dinheiro, materiais de higiene pessoal e limpeza doméstica; ofertas de novas formas de geração de emprego e renda no próprio lar;campanhas de conscientização sobre isolamento social, higiene, uso de máscaras etc. As novas tecnologias permitem dar visibilidade e voz a essas mulheres através das postagens em sites e redes sociais, e conversas em lives. Muitas mulheres em situação de pobreza não possuem acesso à internet e telefonia móvel, o que requer a integração dessas novas tecnologias com outros meios de comunicação e informação tradicionais de áudio e vídeo, alto-falantes e rádios comunitárias (ONU BRASIL, 2020; CUFA, 2020).

Os destaques apresentados são exemplos de ações que transformaram as restrições e impactos advindos com a pandemia, em oportunidades de mudar vidas, defender e garantir os direitos das mulheres, através do poder de alcance, visibilização e influência das tecnologias. 
Em meio às situações de grandes dificuldades e complexidades sociais, de práticas discriminatórias e opressivas e de descaso e inércia estatal, existe a impressão de que estas podem levar ao desalento e descrença na capacidade humana de agir e reagir com ações e atitudes positivas e transformadoras.Todavia, a capacidade de empatia, de acolhimento, de solidariedade e de respeito à dignidade fazem com que a humanidade organizese e reorganize-se em busca de sociedades mais justas e democráticas, em defesa das oportunidades de desenvolvimento e bem estar com liberdades e igualdade para todas as pessoas.

A igualdade de gênero mediante a defesa e garantia dos direitos das mulheres são essenciais para superar a crise pandêmica, pois possibilitará uma recuperação mais rápida e a construção de um futuro melhor para todas as pessoas. Nessa perspectiva, as tecnologias proporcionam aprimorar a colaboração e a cooperação entre as pessoas. Para as mulheres representam um fortalecimento na resposta contra os impactos da Covid-19 em suas vidas, para o empoderamento social e econômico.

\section{Considerações finais}

O momento atual é de incertezas e angústias, que podem levar a um empobrecimento do humano, do sensível, das virtudes morais gerais e dos valores éticos planetários. Para o pós-pandemia o cenário traçado é de incertezas mundiais em relação às atividades humanas, suas interações e 0 desenvolvimento econômico. Contudo, sabe-se ser necessário promover e garantir para todos os seres humanos condições de sobrevivência e desenvolvimento em ambiente de respeito, paz, igualdade, liberdade e justiça social.

A justiça e a cidadania não estão restritas à área do Direito, do jurídico formal de acesso e prática via ação estatal.O afeto e a empatiasão necessários como sentimentos essenciais para que haja a preocupação sensível com o outro, por sua dignidade. É neste sentido que a sororidade estabelece-se sobre os valores de equidade, solidariedade, democracia, cidadania e justiça social. Possui bases democráticas e inclusivas, incorpora o cuidado e elementos diversificados e 
plurais para o combate e enfrentamento dos problemas de discriminações e violações de direitos das mulheres. Enfrentá-los como problemas de ordem social, econômica e política, como problemas relacionados aos direitos fundamentais para o ser humano.

A sororidade é uma perspectiva otimista em direção a avanços e novos impulsionamentos para a efetivação e geração dos direitos à igualdade, liberdade e dignidade das mulheres, pelos movimentos de mulheres e de feministas, pela sociedade como um todo em defesa da humanidade. Para isto, necessita da educação e das tecnologias como facilitadores de seus processos de novas aprendizagem, adaptações e aquisições sociais de novas capacidade, consciência e atitudes transformadoras libertadoras e igualitárias.

A utilização das tecnologias para a defesa dos direitos das mulheres em tempos de pandemia representa processos de educação, comunicação, empoderamento, inclusão e solidariedade digital. Sob essa perspectiva, essa doença demonstrou a importância das conexões para que a humanidade supere as crises com solidariedade utilizando o que de melhor tem construído e inventado em prol das pessoas vulnerabilizadas pelas desigualdades sociais. Demonstra as possibilidades de se ser e ter sociedades inclusivas e sem discriminações, capazes de modificar suas estruturas e sistemas. Portanto, no caso das mulheres, em prol dos princípios democráticos de liberdade, igualdade e sororidade.

\section{Referências}

ALVES, Simone Silva. Saberes das mulheres veteranas na economia solidária.2014. 174p. Tese (Doutorado em Educação) - Faculdade de Educação, Universidade Federal do Rio Grande do Sul, Porto Alegre, 2014.

BRASIL. Constituição da República Federativa do Brasil de 1988. Disponível em:<https://www2.camara.leg.br/atividadeegislativa/legislacao/constituicao19 88.html/arquivos/ConstituicaoTextoAtualizado_EC\%20105.pdf>. Acesso em: 25 mar. 2020. 
CANEL, Regina Célia; CASTRO, Claúdio Gastão Junqueira.A advocacia em saúde como uma estratégia para a promoção da saúde. Revista de Direito Sanitário, São Paulo, v. 9, n.1, p. 74-85, mar./jun. 2008.

CARDOSO, Alenilton da Silva. O princípio da solidariedade: o paradigma ético do direito contemporâneo.São Paulo: Juarez de Oliveira, 2010.

CARVALHO, Lizia de Oliveira; RODRIGUEZ, NidiaBustillos. Comunicadoras indígenas e afrodescendentes latino-americanas: sororidade e identidades. In: Seminário Internacional Fazendo Gênero 11 \& 13th Women's Worlds Congress, 2017, Florianópolis. Anais Eletrônicos. Disponível em: <http://www.wwc2017.eventos.dype.com.br/resources/anais/1499987218_arq uivo_

comunicadorasindigenaseafrodescendenteslatinoamericanassororidadeeidentidades.pdf>. Acesso em: 26 out. 2018.

CONSELHO NACIONAL DE JUSTIÇA - CNJ. [2020]. Justiça reforça divulgação de canais para denunciar violência doméstica. Disponível em: <https://www.cnj.jus.br/category/noticias/cnj/>. Acesso em: 10 abr. 2020.

CENTRAL ÚNICA DAS FAVELAS - CUFA. 20 mil mulheres serão contempladas com R $\$ 120$, valor que se chamará 'vale mãe' em 18 estados brasileiros por dois meses. Disponível em: <https://www.cufa.org.br/noticia.php?n=Mjc1>. Acesso em: 10 abr. 2020.

FUNDAÇÃO OSWALDO CRUZ - FIOCRUZ. Violência doméstica e familiar na COVID-19. Disponível em: <https://www.fiocruzbrasilia.fiocruz.br/wpcontent/uploads/2020/04/Sa\%C3\%BAde-Mental-e-Aten\%C3\%A7\%C3\%A30Psicossocial-na-Pandemia-Covid-19-viol\%C3\%AAncia-dom\%C3\%A9stica-efamiliar-na-Covid-19.pdf>. Acesso em: 21jun. 2020.

GUTERRES, António. Lidando com a desigualdade pandêmica - um novo contrato social para uma nova era. Disponível em: 
$<$ https://nacoesunidas.org/artigo-lidando-com-a-desigualdade-pandemica-umnovo-contrato-social-para-uma-nova-era/>. Acesso em: 12 jul. 2020.

KAMIMURA, Akemi; ANDRADE, Cleide Lugarini; VEÇOSO, Fabia; PRATA, HenriqueMoraes; VIEIRA, Oscar Vilhena; GHIRARDI, José Garcez; FEFERBAUN, Marina. Direitos humanos e vida cotidiana. Rio de Janeiro: Editora FGV,2017.

LAGARDE, Marcela. Sororidad. In: CASTRO, Amanda Motta; MACHADO, Rita de Cassia (Orgs.). Estudos Feministas, mulheres e Educação Popular. Curitiba: CRV, 2016.

MINISTÉRIO DA MULHER, DA FAMÍLIA E DOS DIREITOS HUMANOS MMFDH. [2020]. Recomendações em relação às ações de enfrentamento à violência contra meninas e mulheres no contexto da pandemia de COVID-19. Disponível em: <https://www.gov.br/mdh/pt-br/assuntos/noticias/20202/marco/ministerio-recomenda-que-organismosde-politicas-para-mulheresnao-paralisem-atendimento/SEI_MDH1136114.pdf>. Acesso em: 21 jun. 2020.

MORAES, Maria Celina Bodin de. O princípio da solidariedade. In: MATOS, Ana Carla Harmatiuk. (Org.). A construção dos novos direitos. Porto Alegre: Nuria Fabris, 2008.

MORGADO, Renato Pellegrini; GOZETTO, Andréa Cristina Oliveira.Guia para a Construção de Estratégias de Advocacy: como influenciar políticas públicas.Piracicaba: Imaflora, 2019. Disponível em: $<$ https://www.imaflora.org/biblioteca?page $=1$ \&pesquisa=advocacy $>$ Acesso em: 10 jun. 2020.

ORGANIZAÇÃO DAS NAÇÕES UNIDAS - ONU. Policy brief: the impact of covid-19 on women. Disponível em: <https://www.un.org/sites/un2.un.org/files/policy_brief_on_covid_impact_ on_women_9_apr_2020_updated.pdf $>$. Acesso em: 10 abr. 2020. 
ORGANIZAÇÃO DAS NAÇÕES UNIDAS NO BRASIL - ONU BRASIL. Pensando no coletivo, favelas se organizam para combater o coronavírus. Disponível em: <https://nacoesunidas.org/pensando-no-coletivo-favelas-seorganizam-para-combater-o-coronavirus/>. Acesso em: 11 maio 2020.

ONU MULHERES. [s.d.]. Entidade das Nações Unidas para a Igualdade de Gênero e o Empoderamento das Mulheres. Documentos de referência. Disponível em: <http://www.onumulheres.org.br/onu-mulheres/documentosde-referencia/>. Acesso em: 21jun. 2020.

UNITE NATIONS - UN. [2020]. Roadmap for digital cooperation. Disponível em:<https://www.un.org/en/content/digital-cooperation-

roadmap/assets/pdf/Roadmap_for_Digital_

Cooperation_EN.pdf $>$. Acesso em: 12 jul. 2020. 